\title{
INFLUENCE OF WARM-UP PRIOR TO INCREMENTAL EXERCISE TEST ON AEROBIC PERFORMANCE IN PHYSICALLY ACTIVE MEN
}

\author{
NATALIA DANEK, KAMIL MICHALIK, RAFAŁ HEBISZ, MAREK ZATOŃ \\ University School of Physical Education in Wroclaw, Faculty of Physical Education, \\ Department of Physiology and Biochemistry, Wroctaw, Poland
}

\author{
Mailing address: Natalia Danek, University School of Physical Education in Wroclaw, Department of Physiology \\ and Biochemistry, 35 Paderewskiego Street, 51-612 Wroclaw, tel.: +48 71 3473359, fax: + 4871 3473036, \\ e-mail: natalia_danek@interia.pl
}

\begin{abstract}
Introduction. The aim of the study was to verify the influence of warm-up before a ramp incremental exercise test with linearly increasing loads on the maximal values of physiological variables which determine performance. Material and methods. Thirteen healthy and physically active male students (age $=23.3 \pm 1.5$ years, body height $=179.1 \pm 8.6 \mathrm{~cm}$ and body mass $=79.5$ $\pm 9.1 \mathrm{~kg}$ ) completed a cross-over comparison of two incremental exercise test interventions - an incremental exercise test with a 15-minute warm-up at an intensity of $60 \%$ of the maximal oxygen uptake obtained in the first incremental exercise test and the same test without warm-up. Results. The peak values of physiological variables were statistically significantly higher for the incremental exercise test with warm-up, the differences between tests being $2.66 \%$ for peak power output $(\mathrm{p}=0.039, \mathrm{t}=2.312$, $\mathrm{ES}=0.24), 7.75 \%$ for peak oxygen uptake $(\mathrm{p}=0.000, \mathrm{t}=5.225, \mathrm{ES}=0.56), 7.72 \%$ for peak minute ventilation $(\mathrm{p}=0.005, \mathrm{t}=$ $3.346, \mathrm{ES}=0.53)$ and $1.62 \%$ for peak heart rate $(\mathrm{p}=0.019, \mathrm{t}=2.690, \mathrm{ES}=0.60)$. Conclusions. Warm-up before a ramp incremental exercise test resulted in higher values of maximal oxygen uptake, maximal minute ventilation, maximal heart rate and peak power output.
\end{abstract}

Key words: warm-up, incremental test, physical performance, maximal oxygen uptake

\section{Introduction}

Maximal oxygen uptake $\left(\mathrm{VO}_{2} \mathrm{max}\right)$ is a parameter which is widely used for assessing cardiorespiratory fitness [1]. It makes it possible to determine the potential for performing long-lasting effort $[2,3]$ and select adequate loading in recreational and sports training [4]. Thus, it is important to determine reliable values of $\mathrm{VO}_{2}$ and the factors which determine it. These include the difference in arterio-venous oxygen saturation (a- $\mathrm{VO}_{2}$ diff), cardiac output (Q) [5], minute ventilation, the surface area of the pulmonary capillary network in the lungs and muscles and the level of haemoglobin in the blood.

Incremental exercise tests are a common method of measuring maximal oxygen uptake $\left(\mathrm{VO}_{2} \mathrm{max}\right)$, the factors which affect it and maximal aerobic power [6]. The reliability of $\mathrm{VO}_{2} \max$ measurement is verified in the plateau phase of maximal oxygen uptake [7]. Until recently, the accuracy of measurements was also evaluated on the basis of secondary criteria: the respiratory exchange ratio (RER) exceeding 1.1, peak heart rate over 90\% of the anticipated maximal heart rate and peak blood lactate concentration higher than $8 \mathrm{mmol} \cdot \mathrm{l}^{-1}[8]$. The values of the parameters measured can also be affected by the type of endurance training [1]. Yoon et al. [9] suggested that the test should take up to $12 \mathrm{~min}$ for non-training participants, as any longer effort may result in fatigue and influence oxygen uptake. On the other hand, it was shown in individual cases that a verification phase (a second effort to be performed at an intensity higher than the incremental test) is a practical and sensitive method of confirming $\mathrm{VO}_{2} \mathrm{max}$, which allows for the achievement of higher values of peak oxygen uptake compared to an incremental exercise test (IET) $[7,10]$. It can be presumed that in such a situation, the main phase of the IET serves as a warm-up for the verification phase. Therefore, it seems reasonable to examine whether warm-up performed prior to an incremental exercise test affects the parameters measured in this test.

Warm-ups are used to increase body temperature and blood flow in the muscles, improve nerve conduction [11] as well as increase the activity of oxidative enzymes, the recruitment of motor units [12] and the kinetics of oxygen uptake [13]. Submaximal loading plays this role in the incremental test [1]. ChwalbińskaMoneta and Hänninen [14] found that an additional warm-up performed prior to an incremental exercise test allows for the achievement of higher power at anaerobic threshold. Previous studies have not, however, investigated the change in peak oxygen uptake and the influencing factors for an incremental exercise test preceded by a moderate, low-intensity warm-up.

For this reason, the current study aimed to verify the differences in maximal and submaximal values of physiological variables between an incremental exercise test (IET) with linearly increasing loading and the same test preceded by warm-up $\left(\right.$ IET $\left._{\mathrm{Wu}}\right)$.

\section{Materials and methods}

\section{Participants}

Thirteen healthy active male students, who performed a minimum of 5 hours of exercise per week, participated in the study. All were physically active, but none of them participated in regular sporting competitions during the study period. Information concerning weekly physical activity in the last month before the experiment was collected by means of a questionnaire. The participants performed three tests, each separated by 
a week. The tests were carried out at the Laboratory of Exercise Research (PN-EN ISO 9001:2001 Certificate). The experiment was approved by the University Research Ethics Committee and the study design adhered to the Declaration of Helsinki. The participants provided their written informed consent to participate in the study. They abstained from drinking alcohol during the entire study and did not perform any heavy physical activity $48 \mathrm{~h}$ before the test. They did not consume caffeine $24 \mathrm{~h}$ before the test. The participants arrived at the laboratory at least $2 \mathrm{~h}$ after their last meal. During the initial visit, all the subjects $(n=13)$ performed the IET on a cycle ergometer so that they could become familiar with the equipment and test and so that their performance could be determined. During the following

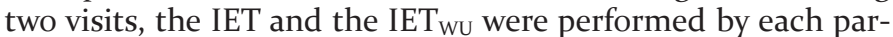
ticipant according to a cross-over study design. Six randomly selected participants performed the IET first and the IET $_{\text {wu }}$ a week later and the order was reversed for the remaining participants. Table 1 presents data concerning the selected anthropometric parameters and the weekly physical activity of the participants.

Table 1. Participant characteristics $(\bar{x} \pm$ SD)

\begin{tabular}{|l|c|}
\hline \multicolumn{1}{|c|}{ Variable } & Value \\
\hline Age (years) & $23.3 \pm 1.5$ \\
Body height $(\mathrm{cm})$ & $179.1 \pm 8.6$ \\
Body mass $(\mathrm{kg})$ & $79.5 \pm 9.1$ \\
VO2peak $\left(\mathrm{ml} \cdot \mathrm{kg}^{-1} \cdot \mathrm{min}^{-1}\right)$ & $50.31 \pm 5.43$ \\
PPO (W) & $347 \pm 38$ \\
Physical activity (h per week) & $8 \pm 2.5$ \\
\hline
\end{tabular}

$\mathrm{VO}_{2}$ peak - peak oxygen uptake expressed in $\mathrm{ml} \cdot \mathrm{kg}^{-1} \cdot \mathrm{min}^{-1}$; PPO - peak power output.

\section{Incremental exercise test (IET)}

Measurements of body mass and height were taken with WPT 200 medical scales (RADWAG, Poland). The IET was performed on an Excalibur Sport electronically-braked cycle ergometer (Lode BV, Netherlands). The workload was increased linearly by $0.27(7) \mathrm{W} \cdot \mathrm{s}^{-1}$ (RAMP protocol) [15]. Effort was performed until a cadence of $60 \mathrm{rpm}$ could not be maintained due to participant refusal or volitional exhaustion. Recording of the respiratory parameters started $3 \mathrm{~min}$ before the task. During the test, participants breathed through a mask connected to a Quark $b^{2}$ device (Cosmed, Italy). The analyser was calibrated with an ambient air and gas mixture of $\mathrm{CO}_{2}(5 \%), \mathrm{O}_{2}(16 \%)$ and $\mathrm{N}_{2}(79 \%)$. Oxygen uptake $\left(\mathrm{VO}_{2}\right)$ and carbon dioxide production $\left(\mathrm{VCO}_{2}\right)$ were measured and the respiratory exchange ratio (RER) was calculated. The plateau response was determined using previously established methods and designated as the period when $\mathrm{VO}_{2}$ did not fluctuate $\leq 1.5 \mathrm{ml} \cdot \mathrm{kg}^{-1} \mathrm{~min}^{-1}$ from the $\mathrm{VO}_{2} \mathrm{max}$ [16]. This analysis was performed with data averaged every $15 \mathrm{~s}$. The time of achieving plateau $\mathrm{VO}_{2} \mathrm{max}\left(\mathrm{T}_{\text {plateau }} \mathrm{VO}_{2}\right)$ was calculated in seconds. Heart rate (HR) was monitored with a Polar S810 sport tester and recorded using Quark. Blood pressure was measured during rest periods and immediately after the test with an aneroid sphygmomanometer (Riester, Germany). Stroke volume (SV) was calculated using Starr's equation [17]: SV $=101+(0.50$. HRP) - (0.59.DP) - (0.6lage), where: SV - stroke volume (ml); HRP - heart rate pressure, that is the difference between systolic and diastolic pressure $(\mathrm{mmHg})$; and DP - diastolic pressure $(\mathrm{mmHg})$; age was entered in years. Cardiac output (Q) was cal- culated based on the following formula: $Q=$ SV.HRpeak, where $\mathrm{Q}$ - cardiac output $\left(\mathrm{ml} \cdot \mathrm{mi}^{-1}\right), \mathrm{SV}$ - stroke volume $(\mathrm{ml})$, and HRpeak - peak heart rate. The arterio-venous difference in oxygen saturation $\left(\mathrm{a}-\mathrm{vO}_{2}\right.$ diff $)$ was verified with a model based on Fick's equation, which used oxygen uptake and cardiac output [18]: $\mathrm{a}-\mathrm{vO}_{2}$ diff $=\mathrm{VO}_{2}$ peak $\cdot \mathrm{Q}^{-1}$.

All the parameters obtained in the IET were measured breath by breath and averaged over 30s. The highest values of the parameters obtained in all tests were treated as peak values. These were VEpeak - maximal minute ventilation, VTpeak - peak tidal volume, Rfpeak - peak respiratory frequency, VO2peak - peak oxygen uptake, HRpeak - peak heart rate, RERpeak - peak respiratory exchange ratio and $\mathrm{PPO}$ - peak power output.

Incremental exercise test with warm-up (IET $\left.T_{\mathrm{WU}}\right)$

A 15-minute warm-up was performed before the incremental exercise test at $60 \%$ of the maximum aerobic power obtained in the first incremental test, which was $\sim 150 \mathrm{~W}$. Cadence ranged from 60 to $90 \mathrm{rpm}$. The recording of respiratory parameters started 3 min prior to warm-up. Next, a participant waited 5 min to start the basic test (described above).

\section{Statistical analysis}

Data were processed with Statistica 13.3 (StatSoft, USA). Means $(\bar{x})$ and standard deviations (SD) were calculated for all the variables that were measured and calculated. The distribution of the data set was screened for normality using the Shapiro-Wilk test. Levene's test was applied to test the assumption of the homogeneity of variance. Student's t-test was used in the evaluation of the differences between the IET and IET wu $_{\text {tests. }}$ The correlation between independent variables ( $\triangle$ VEpeak, $\Delta$ HRpeak, $\Delta \mathrm{SV}, \Delta \mathrm{a}-\mathrm{vO}_{2}$ diff and $\left.\Delta \mathrm{PPO}\right)$ and the dependent variable $\left(\Delta \mathrm{VO}_{2}\right.$ peak) was calculated with multiple regression. Statistical significance was set at $\mathrm{p}<0.05$. G-Power was used to determine the sample size, so that the magnitude of the effect was large $(f=0.8)$, the acceptable statistical error was $\alpha=0.05$ and the strength was $90 \%$. The minimum number of respondents, maintaining the above requirements, was 11 ; however, 13 persons were included in the study to account for potential dropouts.

Statistical significance was set at $\mathrm{p}<0.05$. Effect size (ES), that is Cohen's $d$, was calculated in order to explore the practical effect, using the following criteria: 0.1 - trivial, 0.2 - small, 0.5 - medium and 0.8 - large.

\section{Results}

There was a significant difference between the incremental test with warm-up and the test without warm-up in the absolute PPO value, which was $9 \mathrm{~W}$ higher in the $\operatorname{IET}_{\mathrm{wU}}(\mathrm{p}=0.039$, $\mathrm{t}=2.312$, ES $=0.24$ ). Significant differences were also found for VEpeak values and $\mathrm{VO}_{2}$ peak values, which were higher by 12.52 $1 \cdot \mathrm{min}^{-1}(\mathrm{p}=0.005, \mathrm{t}=3.346, \mathrm{ES}=0.53)$ and $3.98 \mathrm{ml} \cdot \mathrm{kg}^{-1} \cdot \mathrm{min}^{-1}$ $(\mathrm{p}=0.000, \mathrm{t}=5.225, \mathrm{ES}=0.56)$, respectively, for the $\mathrm{IET}_{\mathrm{wU}}$ than for the basic test. There was also a statistically significant increase of $3 \mathrm{bpm}$ in the $\operatorname{IET}_{\mathrm{WU}}(\mathrm{p}=0.019, \mathrm{t}=2.690, \mathrm{ES}=0.60)$. No statistically significant differences were found between the values of VTpeak, Rfpeak and RERpeak in the two tests (Tab. 2).

Stroke volume (SV) and cardiac output (Q) calculated with Starr's equation did not show any statistically significant difference between the tests (Tab. 3). However, $\Delta$ VEpeak, $\Delta$ HRpeak, $\Delta \mathrm{SV}$ and $\Delta \mathrm{a}-\mathrm{vO}_{2}$ diff between the IET $\mathrm{wu}_{\mathrm{w}}$ and the IET correlated with $\Delta \mathrm{VO}_{2}$ peak $\left(\mathrm{r}^{2}=0.82\right)(\mathrm{Tab} .4)$. 
Table 2. Selected physiological parameters in incremental exercise test (IET) and incremental exercise test with warm-up (IET wu $_{\text {) }}$

\begin{tabular}{|c|c|c|c|}
\hline Variable & IET & IETWU & $\Delta(\%)$ \\
\hline PPO (W) & $350 \pm 38$ & $360 \pm 38^{*}$ & 2.66 \\
\hline VEpeak $\left(I \cdot \mathrm{min}^{-1}\right)$ & $162.08 \pm 25.08$ & $174.6 \pm 22.00^{*}$ & 7.72 \\
\hline VTpeak (I) & $3.30 \pm 0.61$ & $3.33 \pm 0.55$ & 0.90 \\
\hline Rfpeak (breath·min ${ }^{-1}$ ) & $54.35 \pm 9.98$ & $57.74 \pm 7.72$ & 6.24 \\
\hline $\mathrm{VO}_{2}$ peak $\left(\mathrm{ml} \cdot \mathrm{kg}^{-1} \cdot \mathrm{min}^{-1}\right)$ & $51.37 \pm 6.46$ & $55.35 \pm 7.71^{*}$ & 7.75 \\
\hline $\mathrm{TplateauVO}_{2}(\mathrm{~s})$ & $13.85 \pm 23.29$ & $13.85 \pm 19.81$ & 0.00 \\
\hline HRpeak (bpm) & $185 \pm 5$ & $188 \pm 5^{*}$ & 1.62 \\
\hline RERpeak & $1.15 \pm 0.04$ & $1.15 \pm 0.04$ & 0.00 \\
\hline
\end{tabular}

PPO - peak power output; VEpeak - peak minute ventilation; VTpeak - peak tidal volume; Rfpeak - peak respiratory frequency; $\mathrm{VO}_{2}$ peak - peak oxygen uptake expressed in $\mathrm{ml} \cdot \mathrm{kg}^{-1} \cdot \mathrm{min}^{-1} ; \mathrm{T}_{\text {Plateau }} \mathrm{VO}_{2}$ - plateau oxygen uptake; HRpeak - peak heart rate; RERpeak - peak exercise respiratory exchange ratio; $\Delta(\%)$ - average percentage differences between tests; * - statistically significant difference between IET and $\operatorname{IET}_{\mathrm{WU}}(\mathrm{p}<0.05)$.

Table 3. Stroke volume (SV) and cardiac output (Q) after IET and IET WU calculated using Starr's equation

\begin{tabular}{|l|c|c|c|}
\hline \multicolumn{1}{|c|}{ Variable } & IET & IETWU & $\Delta(\%)$ \\
\hline SVpeak $(\mathrm{ml})$ & $130.33 \pm 19.25$ & $138.91 \pm 23.11$ & 6.58 \\
Qpeak $\left(l \cdot \mathrm{m}^{-1}\right)$ & $24.19 \pm 3.86$ & $26.12 \pm 4.16$ & 7.99 \\
a-vO diffpeak $(\mathrm{ml})^{16.85 \pm 2.51}$ & $16.85 \pm 3.08$ & 0.00 \\
\hline
\end{tabular}

SVpeak - peak stroke volume calculated using the equation proposed by Starr; Qpeak - peak cardiac output calculated using Starr's equation; a-vO $\mathrm{v}_{2}$ diffpeak - peak arteriovenous difference in oxygen saturation; $\Delta(\%)$ - average percentage difference between tests.

Table 4. Partial correlations between differences in selected parameters obtained in IET and IET $_{W u}$ and difference in peak oxygen uptake between these tests

\begin{tabular}{|c|c|}
\hline Variable & $\begin{array}{c}\Delta V O_{2} \text { peak } \\
\left(\mathrm{ml} \cdot \mathrm{min}^{-1} \cdot \mathrm{kg}^{-1}\right)\end{array}$ \\
\hline$\Delta$ VEpeak $\left(I \cdot \mathrm{min}^{-1}\right)$ & $0.197^{*}(p=0.045)$ \\
\hline$\Delta$ HRpeak (bpm) & $0.228(p=0.375)$ \\
\hline$\Delta$ SVpeak (ml) & $0,603(p=0.061)$ \\
\hline$\Delta \mathrm{a}-\mathrm{vO}_{2}$ diffpeak $(\mathrm{ml})$ & $0.529^{*}(p=0.023)$ \\
\hline$\triangle \mathrm{PPO}(\mathrm{W})$ & $0.035(p=0.909)$ \\
\hline
\end{tabular}

$\Delta \mathrm{VO}_{2}$ peak - difference in peak oxygen uptake between IET ${ }_{\text {wu }}$ and IET; $\Delta \mathrm{VEpeak}$ -

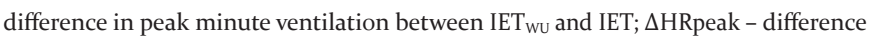
in the peak heart rate between IET $_{\mathrm{Wu}}$ and IET; $\Delta$ SVpeak - difference in peak stroke volume between IET $\mathrm{WU}_{\mathrm{WU}}$ and IET; $\Delta \mathrm{a}-\mathrm{vO}_{2}$ diffpeak - arterio-venous difference in oxygen

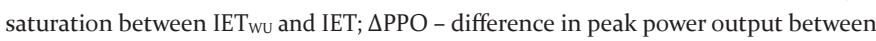
IET $_{\mathrm{WU}}$ and IET; * - parameters having significant influence on $\Delta \mathrm{VO}_{2}$ peak $(\mathrm{p}<0.05)$.

\section{Discussion}

The results obtained in this study seem important for analysing the performance of physically active people, since they show the correct direction in creating incremental exercise tests in order to achieve reliable results. Some authors have conducted research investigating incremental exercise tests preceded by warm-up $[19,20]$, while others have not applied such a practice $[21,22]$. To our knowledge, no study to date has investigated which method provides more robust results. In the IET, submaximal work is performed before reaching the maximal oxygen uptake and maximal aerobic power. It can be used as a warm-up, since such an effort lasting several minutes allows for more powerful, intense aerobic $[23,24]$ and anaerobic efforts [25]. The results obtained in this study showed that an incremental exercise test with an additional warm-up allowed the participants to obtain a higher peak value of PPO and $\mathrm{VO}_{2}$ peak as opposed to the test without warm-up. This indicates that the submaximal effort in the incremental exercise test may not be sufficient for measuring real maximum parameters in physically active people.

Some authors have investigated the factors which determine the importance of warm-up in muscle power and oxygen uptake. According to Tillin and Bishop [26], warming-up increases core body temperature, which affects the strength and speed of muscle contraction. Pearson et al. [27] suggested that higher muscle temperature expands the blood vessels and increases muscle blood flow. As demonstrated by Jones et al. [28], it improves oxygen transport to the working muscles, which is regarded as enhancing the kinetics of oxygen uptake. Johnson et al. [29] reported an increase in enzyme activity in oxidative metabolism. Moreover, Febbraio et al. [30] have claimed that warm-up increases muscle temperature and improves the efficiency of muscle glycolysis and high-energy phosphate degradation during exercise. Some authors have carried out analyses investigating the importance of changes in cardiorespiratory parameters in increasing oxygen uptake and maximal aerobic power in tests with warm-up [13, 31]. We have found that the coefficient of determination $\left(\mathrm{r}^{2}\right)$ for the difference in peak oxygen uptake was 0.82. This was if the differences between the IET

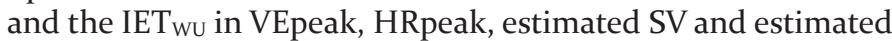
$\mathrm{a}-\mathrm{vO}_{2}$ diff were explanatory variables. Partial correlations indicate that a higher value of $\mathrm{VO}_{2}$ peak in the IET $_{w U}$ is largely determined by the increase in peak minute ventilation and the ability to maintain or increase the estimated arterio-venous difference in oxygen saturation compared to the IET.

The analyses did not find evidence of significant correlations between changes in cardiorespiratory parameters and the difference in PPO between tests. This indicates that greater oxygen supply to the muscles and their use were not the main factors explaining the effect of warm-up on peak power output. It is possible that in this case, the activity of anaerobic metabolism, which increases as a result of warming-up, is also important [30]. Power can also be dependent on work efficiency, which can be greater among athletes with relatively low $\mathrm{VO}_{2}$ peak [3]. Such a change may have occurred in the research carried out by the current authors on physically active subjects who showed a relatively small change in $\mathrm{VO}_{2}$ max.

The analysis of the results obtained presents some limitations, such as the small number of subjects and the application of indirect methods in anticipating stroke volume and the difference in arterio-venous oxygen saturation. 


\section{Conclusion}

In conclusion, the use of a 15-minute warm-up at an intensity of $60 \%$ of aerobic power $(-150 \mathrm{~W})$ prior to an incremental exercise test resulted in higher peak aerobic power and oxygen uptake. The factors which determined higher $\mathrm{VO}_{2}$ peak values were changes in the following cardiorespiratory parameters: VEpeak, HRpeak, estimated stroke volume and arterio-venous difference in oxygen saturation.

\section{Literature}

1. Beltz N.M., Gibson A.L., Janot J.M., Kravitz L., Mermier C.M., Dalleck L.C. (2016). Graded exercise testing protocols for the determination of $\mathrm{VO}_{2}$ max: Historical perspectives, progress, and future considerations. Journal of Sports Medicine 2016, Article ID 3968393. DOI: 10.1155/2016/3968393.

2. Joyner M.J., Coyle E.F. (2008). Endurance exercise performance: The physiology of champions. The Journal of Physiology 586, 35-44. DOI: 10.1113/jphysiol.2007.143834.

3. Lucia A.O., Hoyos J., Pérez M., Santalla A., Chicharro J.L. (2002). Inverse relationship between $\mathrm{VO}_{2}$ max and economy/efficiency in world-class cyclists. Medicine $\mathcal{E}$ Science in Sports E Exercise 34(12), 2079-2084. DOI: 10.1249/01. MSS.0000039306.92778.DF.

4. Foster C., Rodriguez-Marroyo J.A., De Koning J.J. (2017). Monitoring training loads: The past, the present, and the future. The International Journal of Sports Physiology and Performance 12(2), 2-8. DOI: 10.1123/IJSPP.2016-0388.

5. Levine B.D. (2008). $\mathrm{VO}_{2}$ max: What do we know, and what do we still need to know? The Journal of Physiology 586(1), 25-34. DOI: 10.1113/jphysiol.2007.147629.

6. Bentley D.J., Newell J., Bishop D. (2007). Incremental exercise test design and analysis. Sports Medicine 37(7), 575586. DOI: 10.2165/00007256-200737070-00002.

7. Midgley A.W., Carroll S. (2009). Emergence of the verification phase procedure for confirming 'true' $\mathrm{VO}_{2}$ max. Scandinavian Journal of Medicine $\mathcal{E}$ Science in Sports 19(3), 313322. DOI: 10.1111/j.1600-0838.2009.00898.x.

8. Poole D.C., Wilkerson D.P., Jones A.M. (2008). Validity of criteria for establishing maximal $\mathrm{O}_{2}$ uptake during ramp exercise tests. European Journal of Applied Physiology 102(4), 403-410. DOI: 10.1007/s00421-007-0596-3.

9. Yoon B., Kravitz L., Robergs R. (2007). $\mathrm{VO}_{2} \mathrm{max}$, protocol duration and the $\mathrm{VO}_{2}$ plateau. Medicine $\mathcal{E}$ Science in Sports $\mathcal{E}$ Exercise 39(7), 1186-1192. DOI: 10.1249/ mss.0bl3e318054e304.

10. Sawyer B.J., Tucker W.J., Bhammar D.M., Gaesser G.A. (2015). Using a verification test for determination of VO${ }_{2}$ max in sedentary adults with obesity. The Journal of Strength E Conditioning Research 29(12), 3432-3438. DOI: 10.1519/JSC.0000000000001199.

11. Pearce A.J., Rowe G.S., Whyte D.G. (2012). Neural conduction and excitability following a simple warm-up. Journal of Science and Medicine in Sport 15(2), 164-168. DOI: 10.1016/j. jsams.2011.09.001.

12. Gurd B.J., Peters S.J., Heigenhauser G.J.F., LeBlanc P.J., Doherty T.J., Paterson D.H. et al. (2006). Prior heavy exercise elevates pyruvate dehydrogenase activity and speeds $\mathrm{O}_{2}$ uptake kinetics during subsequent moderate-intensity exercise in healthy young adults. The Journal of Physiology 577(3), 985-996. DOI: 10.1113/jphysiol.2006.112706
13. Poole D.C., Jones A.M.(2012). Oxygen uptake kinetics. Comprehensive Physiology 2(2), 933-996. DOI: 10.1002/ cphy.cl00072.

14. Chwalbińska-Moneta J., Hänninen O. (1989). Effect of active warming-up on thermoregulatory, circulatory, and metabolic responses to incremental exercise in endurance-trained athletes. International Journal of Sports Medicine 10(01), 25-29. DOI: 10.1055/s-2007-1024868.

15. Michalik K., Danek N., Zatoń M. (2019). Assessment of the physical fitness of road cyclists in the step and ramp protocols of the incremental test. The Journal of Sports Medicine and Physical Fitness 59(8), 1285-1291. DOI: 10.3390/ ijerph16203934.

16. Doherty M., Nobbs L., Noakes T. (2003). Low frequency of the "plateau phenomenon" during maximal exercise in elite British athletes. European Journal of Applied Physiology 89(6), 619-623.

17. Starr I. (1954). Clinical tests of the simple method of estimating cardiac stroke volume from blood pressure and age. Circulation 9(5), 664-681. DOI: 10.1161/01.CIR.9.5.664.

18. Stringer W.W., Hansen J.E., Wasserman K. (1997). Cardiac output estimated noninvasively from oxygen uptake during exercise. Journal of Applied Physiology 82(3): 908-912. DOI: 10.1152/jappl.1997.82.3.908.

19. Brickley G., Dekerle J., Hammond A.J., Pringle J., Carter H. (2007). Assessment of maximal aerobic power and critical power in a single 90-s isokinetic all-out cycling test. International Journal of Sports Medicine 28(05), 414-419. DOI: 10.1055/s-2006-924513.

20. Lanzi S., Codecasa F., Cornacchia M., Maestrini S., Capodaglio P., Brunani A. et al. (2015). Long maximal incremental tests accurately assess aerobic fitness in class II and III obese men. PloS One 10(4), e0124180.

21. Żołądź J.A., Duda K., Majerczak J. (1998). Oxygen uptake does not increase linearly at high power outputs during incremental exercise test in humans. European Journal of Applied Physiology and Occupational Physiology 77(5), 445451. DOI: $10.1007 / \mathrm{s} 004210050358$.

22. Souza K.M., de Lucas R.D., do Nascimento Salvador P.C., Guglielmo L.G.A., Caritá R.A.C., Greco C.C. et al. (2015). Maximal power output during incremental cycling test is dependent on the curvature constant of the power-time relationship. Applied Physiology, Nutrition and Metabolism 40(9), 895-898. DOI: 10.1139/apnm-2015-0090.

23. Bishop D., Bonetti D., Dawson B. (2001). The effect of three different warm-up intensities on kayak ergometer performance. Medicine E Science in Sports E Exercise 33(6), 10261032. DOI: 10.1097/00005768-200106000-00023.

24. Hajoglou A., Foster C., De J.K., Lucia A., Kernozek T.W., Porcari J.P. (2005). Effect of warm-up on cycle time trial performance. Medicine E Science in Sports E Exercise 37(9), 1608-1614. DOI: 10.1249/01.mss.0000177589.02381.0a.

25. Frikha M., Chaari N., Mezghanni N., Souissi N. (2016). Influence of warm-up duration and recovery interval prior to exercise on anaerobic performance. Biology of Sport 33(4), 361. DOI: $10.5604 / 20831862.1221830$.

26. Tillin N.A., Bishop D. (2009). Factors modulating postactivation potentiation and its effect on performance of subsequent explosive activities. Sports Medicine 39(2), 147166. DOI: 10.2165/00007256-200939020-00004.

27. Pearson J., Low D.A., Stöhr E., Kalsi K., Ali L., Barker H. et al. (2010). Hemodynamic responses to heat stress in the resting and exercising human leg: Insight into the effect of temperature on skeletal muscle blood flow. Ameri- 
can Journal of Physiology, Regulatory, Integrative and Comparative Physiology 300(3), 663-673. DOI: 10.1152/ajpregu.00662.2010.

28. Jones A.M., Koppo K., Burnley M. (2003). Effects of prior exercise on metabolic and gas exchange responses to exercise. Sports Medicine 33(13), 949-971. DOI: 10.2165/00007256-200333130-00002.

29. Johnson M.A., Gregson I.R., Mills D.E., Gonzalez J.T., Sharpe G.R. (2014). Inspiratory muscle warm-up does not improve cycling time-trial performance. European Journal of Applied Physiology and Occupational Physiology 114(9), 1821-183. DOI: 10.1007/s00421-014-2914-x.
30. Febbraio M.A., Carey M.F., Snow R.J., Stathis C.G., Hargreaves M. (1996). Influence of elevated muscle temperature on metabolism during intense, dynamic exercise. American Journal of Physiology, Regulatory, Integrative and Comparative Physiology 271(5), 1251-1255. DOI: 10.1152/ajpregu.1996.271.5.R1251.

31. Lima L.P., Leite H.R., de Matos M.A., Neves C.D.C., da Silva Lage V.K., da Silva G.P. et al. (2019). Cardiorespiratory fitness assessment and prediction of peak oxygen consumption by Incremental Shuttle Walking Test in healthy women. PloS One 14(2), e0211327.

Submitted: September 10, 2019.

Accepted: December 22, 2019. 